\title{
KOMUNIKASI BARU BIRO ARSITEK DI MASA PANDEMI DALAM PANDANGAN POSTKOLONIALISME HOMI K BHABHA
}

\author{
Gayuh Budi Utomo ${ }^{1}$, Rully Damayanti ${ }^{2}$, Dyan Agustin $^{3}$ \\ 1,2. Program Studi Magister Arsitektur, Fakultas Teknik Sipil dan Perencanaan, UK Petra \\ Jl. Siwalankerto 121-131 Surabaya \\ 3. Program Studi Arsitektur, Fakultas Arsitektur dan Desain, UPN Veteran Jawa Timur \\ Rungkut Madya Gunung Anyar, Surabaya \\ Email: b22200004@john.petra.ac.id
}

\begin{abstract}
Abstrak
Tatanan baru yang disebut new normal menjadi isu sentral saat ini. Masa sebelum pandemi yang menjadi nilai baku dan menjadi rujukan tiba tiba tidak compatible dengan datang nya wabah pandemi COVID-19. Hal ini terjadi di seluruh dunia juga di Indonesia. Semua berada dalam situasi pandemi dalam jangka waktu tidak ada kepastian akan berakhirnya. Hal ini berimbas pada cara berkomunikasi pada semua aspek termasuk biro arsitek. Cara berkomunikasi baru dilakukan pada biro arsitek terkait social distancing dan physical distancing yang dianggap sebagai metode pencegahan efektif dari pandemi Covid-19. Jenis komunikasi yang berubah adalah komunikasi dengan klien, komunikasi dengan tim dan komunikasi dengan mahasiswa magang. Terdapat perbedaan cara berkomunikasi yang cukup signifikan dari aktivitas luring beralih ke aktivitas daring dimana kita tetap dapat terhubung secara dua arah tetapi tidak dalam satu tempat yang sama. Situasi ini menjadi momentum bebasnya ikatan keterbatasan yang selama ini terjadi dalam hal berkomunikasi. Kami ingin memaknai hal ini dalam pendekatan postkolonialisme menurut Homi K Bhabha yang sangat relevan dengan pandangan hibriditas, ambivalence dan ruang ketiga sebagai cara pandang berkomunikasi wacana baru new normal.
\end{abstract}

Kata kunci: komunikasi , biro arsitek , pandemi, postkolonialisme.

\section{Abstract \\ Title: New Communication of The Architecture Firms in Pandemic Era; Following the Homi K Bhabha Post Colonial View}

A new order called the new normal is a central issue at this time. The period before the pandemic which became a standard value and became a reference suddenly was not compatible with the arrival of the Covid-19 pandemic outbreak. This is happening in Indonesia and around the world. Everyone is in a pandemic situation for a certain period time and there is no certainty that it will end. This of course also affects how to communicate in all aspects including the architectural bureau. New ways of communicating are carried out at architectural bureaus related to social distancing and physical distancing which are considered as effective prevention methods from the COVID-19 pandemic. The types of communication that have changed are communication with clients, communication with the team and communication with interns. There are significant differences in how to communicate from offline activities to online activities where we can still be connected both ways but not in the same place. This situation is a momentum to free the bonds of limitations that have occurred in terms of communication. We want to interpret this in the postcolonialism approach of Homi $K$ Bhabha which is very relevant to the views of hybridity, ambivalence and the third space as a way of communicating new normal discourses.

Keywords: communication, architectural bureau, pandemic, postcolonialism. 


\section{Pendahuluan}

Kata pandemi saat ini menjadi isu sentral dalam media berbagai negara, barat atau non barat semua berada dalam kondisi yang sama. Bahkan negara maju seperti Amerika tercatat total kasus 6,75 jt dan 198rb diantaranya meninggal dunia (The New York times September 2020) dan sampai saat ini masih berjuang keras untuk menurunkannya. Covid-19 adalah wabah yang mampu menyerang seluruh dunia dan sangat berdampak besar bagi seluruh segi kehidupan umat manusia. Hal ini tentunya juga berimbas pada cara berkomunikasi pada semua aspek termasuk biro arsitek. Cara berkomunikasi baru dilakukan pada biro arsitek terkait social distancing dan physical distancing yang dianggap sebagai metode pencegahan efektif dari pandemi Covid-19. Jenis komunikasi yang berubah adalah komunikasi dengan klien, komunikasi dengan tim dan komunikasi dengan mahasiswa magang.

\section{Komunikasi Internal Biro Sebelum Pandemi}

Sebelum pandemi kita berada pada satu tempat (studio) dan waktu yang sama. Dimana proses perencanaan bisa berlangsung intens. Principal arsitek bisa sewaktu waktu melihat perkembangan proses desain bersama timnya sehingga ada beberapa hal kecil bisa dilaksanakan secara simultan. Juga karena proses desain dilaksanakan secara bersama sama sehingga antar junior arsitek bisa saling memberi pendapat untuk mendapatkan hasil rancangan yang maksimal. Dengan menggunakan seluruh perangkat komunikasi kita seperti komunikasi verbal dan nonverbal komunikasi visual, komunikasi sentuhan komunikasi gerak tubuh komunikasi lingkungan dan komunikasi penampilan.

\section{Komunikasi Biro dengan Klien Sebelum Pandemi}

Saat diskusi konsultasi dengan klien dilakukan dengan pertemuan langsung. Bisa di rumah, kantor atau site proyek. Dimana proses komunikasi verbal bisa berlangsung sangat akrab dan hangat. Dengan penjelasan yang bisa lebih detail karena bisa berada dan merasakan langsung.

\section{Komunikasi Biro dengan Mahasiswa Magang Sebelum Pandemi}

Saat sebelum pandemic mahasiswa magang berada di kantor biro arsitek bersama tim untuk menjadi bagian dari tim. Diskusi dilakukan secara langsung melalui rapat baik di kantor maupun di site proyek. Demikian juga hubungan dengan dosen pembimbing magang, dimana dosen pembimbing magang sesekali berkunjung ke tempat biro arsitek untuk melihat dan memantau perkembangan jalannya magang mahasiswa.

\section{Pendekatan Postkolonialisme}

Cara pandang postolonialisme kami pilih sebagai framework dalam membahas perubahan komunikasi. Sebagai relevansi kondisi masyarakat Indonesia yang merupakan negara yang pernah terjajah dari belanda dan jepang. Definisi postkolonial sendiri adalah kumpulan strategi atau cara yang digunakan untuk menganalisa sebuah gejala kultural yang terjadi di negara bekas koloni Eropa modern. Sehingga postkolonial adalah alat untuk melakukan kritik sosial, ekonomi dan budaya pada era pascakolonial. Menurut Bhabha, seorang filsuf kelahiran Mumbay (Bombay) India dalam kumpulan esai yang berjudul The Location of Culture 
(1994). Menurutnya postkolonialisme memunculkan silang budaya dalam banyak bentuk di masyarakat baik intrinsik maupun ekstrinsik. Dua dunia menjadi sentral pemikiran sebagian masyarakat kita, antara Barat dan Timur yang disimbolkan Barat sebagai simbol kebudayan yang modern sedang Timur sebagai simbol tradisional, sehingga menjadi rujukan dalam banyak hal. Datangnya pandemi yang menyerang seluruh negara baik yang pernah menjajah atau yang pernah terjajah semua terserang pandemi ini. Sehingga stigma yang selama ini terbangun menjadi runtuh dan menjadi sama jika kita melihatnya dari pandangan positif. Semangat untuk menjadi sama terbuka lebar dengan situasi saat ini karena new normal masih belum ada referensinya. Semua negara berpotensi sama utk mengatasi pandemi ini dengan cara yang sesuai dengan budaya yg sudah ada baik itu tradisi atau yang diluar tradisi.

\section{Biro Arsitek dan Eksplorasi Arsitektur}

Era baru dalam menggali informasi konsep ide dunia arsitektur sangat terbuka dan berkembang saat pandemi ini. banyaknya diskursus, class online atau seminar seminar yang diadakan institusi pendidikan ataupun non pendidkan secara terbuka menjadi pemicu derasnya arus informasi langsung kepada masyarakat. Hal ini juga kami alami sebagai biro arsitektur. Yang semasa sebelum pandemi kami hanya terhubung dengan beberapa sumber informasi terbatas. Saat pandemi ini sumber informasi baru seperti mengisi kebutuan kebutuhan yang hanya kami dapatkan saat berkunjung ke wilayah wilayah tertentu. Misalnya untuk mengetahui informasi mengenai arsitektur Sasak dapa masa sebelum pandemi ada dua cara yaitu dengan membeli buku tentang Sasak yang sangat susah ditemui di toko buku atau kita mencari sumber dari internet yang tanpa kita bisa tahu secara benar dan valid informasinya. Tetapi dengan banyaknya web-seminar (webinar) yang memberikan banyak informasi informasi tentang apa apa yang kita butuhkan baik itu keperluan sebagai bahan konsep atau juga sebagai wacana dan wawasan keilmuan didalam proses memperkaya khasanah keilmuan berarsitektur kita.

Hal ini akan menjadi dampak positif terhadap ilmu ilmu yang selama ini sangat jarang kami peroleh selain di dalam dunia akademisi. Sehingga wawasan dan keilmuan bisa kita dapatkan dengan sangat mudah dan seimbang karena webinar webinar banyak sekali membahas tentang perkembangan perkembangan arsitektur yang mengangkat nilai nilai kesetempatan dari masyarakat Indonesia.

\section{Metode}

Untuk mendapatkan gambaran akan perubahan yang cukup jelas antara sebelum pandemi dan saat pandemic, kami meneliti bagaimana perubahan dalam proses komunikasi yang dilakukan saat eksplorasi desain yang menjadi proses dominan didalam sebuah biro arsitek di Surabaya. Penelitian ini dilakukan dalam rentang waktu april sampai September 2020. Teknik yang dipakai adalah pengamatan langsung dan wawancara. Dari penelitian ini diharapkan mampu menghasilkan temuan yang berguna untuk meningkatkan kualitas komunikasi saat era new normal. 


\section{Hasil dan Pembahasan}

\section{Kemampuan Mengorganisasikan Informasi-Informasi}

Perubahan komunikasi dalam hubungan sosial berubah menjadi komunikasi interaktif karena terjadi pengkaburan antara produsen, distributor dan konsumen (Poster 1995). Informasi jaringan sangat diperlukan agar mendapatkan ketepatan dalam melihat dalam sudut pandang yang lain (Gilster, 1997). Informasi tersebut harus dirangkai dengan menggunakan masukanmasukan dan sistem umpan balik atau evaluasi. Menurut Groat and Wang (2002) sumber data penelitian kualitatif bisa berupa kata kata yang mengungkapkan makna yang tersirat pada dokumen atau benda.

\section{Eksplorasi Interaktif}

Teknologi komputerisasi juga menjadi hal yang penarik untuk dipakai dalam masa pandemi. Seperti dunia virtual reality menjadi media interaktif tidak menghasilkan pengalaman pengalaman baru mengenai persentasi yang dapat dibangun bersama antara arsitek dan kliennya dalam konteks merasakan ruang, bentuk, dan interpertasi. Media digital memiliki peran terhadap inovasi pengungkap makna dan rancangan yang tak terbatas. Sedangkan waktu menjadi bagian dari sebuah proses. Akan ada sebuah pergeseran makna misalnya dari mimesis ke arah virtualitas, dari interpertasi menuju interaktivitas, dari citra ke interface, serta dari sistem menuju Rhizome (Deleuze and Guattari, 1980).

\section{Ruang Ketiga dan Hibriditas}

Hibriditas dan ruang ketiga (Third Space) dari sebuah analisa kolonialisme antara identitas penjajah dan terjajah sebagai identitas. Homi Bhabha (2007) mencoba menjelaskan ruang antara dua kategori mapan: sang penjajah dan si terjajah dengan menyebut ruang antara sebagai ruang ketiga atau ruang hibriditas ataupun ruang ambang. Di ruang ambang inilah kaum terjajah menemukan strategi perlawanan terhadap dominasi wacana penjajah. Cara yang dilakukan adalah dengan "perselingkuhan" budaya, yaitu dengan mengambil alih tanda-tanda budaya penjajah, tapi diberi isi sehingga menghasilkan identitas dan cara hidup yang baru. Misalnya pemakaian jas (beskap) yang berasal dari Barat dikombinasi dengan jarik yang menjadi pakaian resmi di kalangan priyayi Jawa. Bhabha dalam membentuk ruang ketiga ini tidak mempermasalahkan penindasan kolonialisme yang dilakukan penjajah terhadap si terjajah. Ia lebih mempersoalkan tajamnya pembedaan kedua kategori itu, yang menunjukkan oposisi biner yang telah dikritik oleh pemikir Perancis, Jacques Derrida (1930-2004). Derrida menyatakan wacana Barat didominasi oleh binerisme yang membagi dua identitas misalnya hitam dan putih, timur dan barat, penjajah dan terjajah, laki laki dan perempuan, dan sebagainya. Orientasi tatanan baru telah berubah seiring tuntutan standarisasi baru yang sesuai protocol Covid 19. Hal ini sangat mempengaruhi skala personal hingga interpersonal baik skala cara dan orientasi bersosial hingga cara kita merancang wadah kegiatannya.

\section{Bekerja Jarak Jauh}

Bekerja jarak jauh adalah pekerjaan yang dilakukan oleh seseorang pegawai di sebuah lokasi diluar kantor dengan menggunakan media telekomunikasi sebagai alat kerja (Huuhtanen, 1997). Bekerja jarak jauh merupakan bekerja dalam sebuah organisasi yang dilaksanakan di luar 
kantor konvensional dengan bantuan layanan telekomunikasi dan informasi (DeRossette, 2016). Cara yang diterapkan dalam menjalankan biro arsitek selama pandemi ini dalam kaitannya dengan tim dan mahasiswa magang adalah bekerja jarak jauh. Tentunya hal ini mempunyai kelemahan dan kelebihan. Secara umum manfaat bekerja jarak jauh adalah (Heathfield, 2019):

a. Mendapatkan keleluasaan untuk bercengkerama dengan keluarga dan berkehidupan dengan lebih nyaman

b. Dapat memilih waktu yang tepat berada di kantor dan diluar kantor atau rumah. Dengan demikian dapat menghindari kemacetan dan mengurangi tingkat stres. Selain itu, menghemat waktu dan mengurangi biaya perjalanan

c. Dapat mengatur sendiri jadwal dan lingkungan kerja sehingga terasa seperti wiraswasta. Disamping itu dapat mencegah pekerja menjadi terbebani (overload).

d. Meningkatkan semangat dan komitmen kepada organisasi. Selain mengurangi pergantian pekerja, ketidakhadiran, dan keterlambatan.

e. Terbangun citra pekerja dan dapat meningkatkan peluang mendapatkan pekerja berkualitas.

f. Memungkinkan pekerja memperoleh data dan informasi dari luar kantor.

g. mengurangi biaya operasi kantor, berkurangnya luasan kantor, kebutuhan kursi, meja, komputer, peralatan lainnya.

\section{Komunikasi Biro Arsitek dengan Klien di Era New Normal}

Di era pandemi ini komunikasi dengan klien di jalankan secara daring. Pertemuan langsung biasanya hanya dilakukan saat pertemuan pertama sebagai pendalaman dan survey lokasi.
Tabel 1. Kelebihan dan tantangan konsultasi jarak jauh menurut klien dan biro arsitek

\begin{tabular}{|c|c|c|}
\hline Kategori & Kelebihan & Tantangan \\
\hline Klien & $\begin{array}{l}\text { Dapat bebas } \\
\text { melakukan } \\
\text { waktu diskusi }\end{array}$ & $\begin{array}{l}\text { Terkadang } \\
\text { diluar jam kerja }\end{array}$ \\
\hline \multirow[t]{3}{*}{$\begin{array}{l}\text { Biro } \\
\text { Arsitek }\end{array}$} & $\begin{array}{l}\text { Dapat } \\
\text { mengurangi } \\
\text { biaya } \\
\text { transportasi }\end{array}$ & $\begin{array}{l}\text { Waktu diskusi } \\
\text { akan bertambah } \\
\text { panjang }\end{array}$ \\
\hline & $\begin{array}{l}\text { Dapat } \\
\text { menjelaskan } \\
\text { gambar secara } \\
\text { online }\end{array}$ & $\begin{array}{l}\text { Terkadang } \\
\text { dapat salah } \\
\text { persepsi }\end{array}$ \\
\hline & & $\begin{array}{l}\text { Perubahan atau } \\
\text { perkembangan } \\
\text { desain bisa } \\
\text { berulang ulang }\end{array}$ \\
\hline
\end{tabular}

Sumber: Analisis pribadi

\section{Komunikasi Biro Arsitek dengan Tim di Era New Normal}

Koordinasi dengan tim merupakan hal yang paling utama dalam proses berarsitektur pada biro arsitek. Perubahan cara berkomunikasi dengan tim secara daring ini menghasilkan kelebihan serta tantangan tersendiri. Penyesuaian harus segera dilakukan semua pihak untuk lancarnya koordinasi dengan tim.

Tabel 2. Kelebihan dan tantangan bekerja jarak jauh menurut pekerja dan pemberi kerja

\begin{tabular}{|c|c|c|}
\hline Kategori & Kelebihan & Tantangan \\
\hline \multirow{3}{*}{ Pekerja } & $\begin{array}{l}\text { Mandiri dan } \\
\text { leluasa } \\
\text { menentukan } \\
\text { jadwal kerja }\end{array}$ & $\begin{array}{l}\text { Kesulitan } \\
\text { membedakan } \\
\text { antara } \\
\text { kepentingan } \\
\text { kerja dan } \\
\text { urusan pribadi }\end{array}$ \\
\hline & $\begin{array}{l}\text { Waktu } \\
\text { perjalanan } \\
\text { kekantor } \\
\text { berkurang/ } \\
\text { hilang }\end{array}$ & $\begin{array}{l}\text { Merasa } \\
\text { terisolasi dari } \\
\text { jejaring } \\
\text { sosial kantor }\end{array}$ \\
\hline & $\begin{array}{l}\text { Biaya } \\
\text { perjalanan, } \\
\text { dan parkir } \\
\text { berkurang }\end{array}$ & $\begin{array}{l}\text { Perangkat tidak } \\
\text { lengkap atau } \\
\text { kurang } \\
\text { dukungan } \\
\text { teknis }\end{array}$ \\
\hline
\end{tabular}




\begin{tabular}{|c|c|c|}
\hline & $\begin{array}{l}\text { Lebih } \\
\text { semangat dan } \\
\text { puas bekerja }\end{array}$ & $\begin{array}{l}\text { Interaksi } \\
\text { terbatas dengan } \\
\text { pimpinan yang } \\
\text { dapat } \\
\text { berdampak } \\
\text { pada karir }\end{array}$ \\
\hline & $\begin{array}{l}\text { Terhindar dari } \\
\text { kasak kusuk } \\
\text { kantor (office } \\
\text { politics) }\end{array}$ & $\begin{array}{l}\text { Merasa tidak } \\
\text { disukai oleh } \\
\text { rekan kerja }\end{array}$ \\
\hline \multirow{5}{*}{$\begin{array}{l}\text { Pemberi } \\
\text { Kerja }\end{array}$} & $\begin{array}{l}\text { Produktifitas } \\
\text { pekerja } \\
\text { meningkat }\end{array}$ & $\begin{array}{l}\text { Kesulitan } \\
\text { memantau } \\
\text { kinerja } \\
\text { pekerja }\end{array}$ \\
\hline & $\begin{array}{l}\text { Tingkat } \\
\text { ketidakhadiran } \\
\text { berkurang }\end{array}$ & $\begin{array}{l}\text { Kesulitan } \\
\text { mengukur } \\
\text { tingkat } \\
\text { produktifitas } \\
\text { pekerja }\end{array}$ \\
\hline & $\begin{array}{l}\text { Masa kerja } \\
\text { pekerja } \\
\text { meningkat }\end{array}$ & $\begin{array}{l}\text { Mendorong } \\
\text { perubahan } \\
\text { organisasi } \\
\text { keluar dari } \\
\text { zona nyaman }\end{array}$ \\
\hline & $\begin{array}{l}\text { Lebih banyak } \\
\text { calon pegawai } \\
\text { yang dapat } \\
\text { dipilih }\end{array}$ & $\begin{array}{l}\text { Peluang } \\
\text { dampaknegatif } \\
\text { terhadap } \\
\text { jejaring sosial } \\
\text { kantor }\end{array}$ \\
\hline & $\begin{array}{l}\text { Berkurangnya } \\
\text { biaya kantor }\end{array}$ & $\begin{array}{l}\text { Kesulitan } \\
\text { mendorong } \\
\text { sinergitas Tim }\end{array}$ \\
\hline
\end{tabular}

Sumber: Mungkasa, 2020

Komunikasi Biro Arsitek dengan Mahasiswa Magang di Era New Normal

Komunikasi yang jelas sebenarnya sangat dibutuhkan dalam proses magang ini. Mahasiswa magang sangat membutuhkan arahan untuk pelaksanaan pembelajaran. Dengan pandemi ini tentunya menimbulkan beberapa kesulitan baik dari sisi mahasiswa maupun dari sisi biro arsitek.

Tabel 3. Kelebihan dan tantangan konsultasi jarak jauh menurut mahasiswa magang dan biro arsitek

\begin{tabular}{|l|l|l|}
\hline Kategori & \multicolumn{1}{|c|}{ Kelebihan } & \multicolumn{1}{|c|}{ Tantangan } \\
\hline & Waktu & Merasa \\
& perjalanan & terisolasi dari \\
& kekantor & jejaring \\
\hline
\end{tabular}

\begin{tabular}{|c|c|c|}
\hline \multirow{6}{*}{$\begin{array}{l}\text { Mahasisw } \\
\text { a Magang }\end{array}$} & $\begin{array}{l}\text { berkurang/ } \\
\text { hilang }\end{array}$ & sosial kantor \\
\hline & $\begin{array}{l}\text { Mandiri dan } \\
\text { leluasa } \\
\text { menentukan } \\
\text { jadwal } \\
\text { magang }\end{array}$ & $\begin{array}{l}\text { Kesulitan } \\
\text { membedakan } \\
\text { antarawaktu } \\
\text { magang dan } \\
\text { urusan pribadi }\end{array}$ \\
\hline & $\begin{array}{l}\text { Hemat biaya } \\
\text { transportasi }\end{array}$ & $\begin{array}{l}\text { Terkadang } \\
\text { kurang paham }\end{array}$ \\
\hline & & $\begin{array}{l}\text { Ketersediaan } \\
\text { jaringan } \\
\text { internet }\end{array}$ \\
\hline & & $\begin{array}{l}\text { Kebutuhan } \\
\text { computer yang } \\
\text { tidak selalu } \\
\text { memadai }\end{array}$ \\
\hline & & $\begin{array}{l}\text { Kurang terjalin } \\
\text { ikatan tim }\end{array}$ \\
\hline \multirow{5}{*}{$\begin{array}{l}\text { Biro } \\
\text { Arsitek }\end{array}$} & $\begin{array}{l}\text { Tidak ada } \\
\text { pertemuan } \\
\text { langsung }\end{array}$ & $\begin{array}{l}\text { Kurang bisa } \\
\text { mengikuti } \\
\text { ritme pekerjaan }\end{array}$ \\
\hline & $\begin{array}{l}\text { Tingkat } \\
\text { ketidakhadiran } \\
\text { berkurang }\end{array}$ & $\begin{array}{l}\text { Kesulitan } \\
\text { mengukur } \\
\text { tingkat } \\
\text { produktifitas }\end{array}$ \\
\hline & & $\begin{array}{l}\text { Dibutuhkan } \\
\text { waktu lebih } \\
\text { panjang untuk } \\
\text { menjelaskan }\end{array}$ \\
\hline & & $\begin{array}{l}\text { Tingkat presisi } \\
\text { pekerjaan } \\
\text { kurang bisa } \\
\text { diukur }\end{array}$ \\
\hline & & $\begin{array}{l}\text { Terjadi gab } \\
\text { antara tuntutan } \\
\text { proyek dengan } \\
\text { kemampuan } \\
\text { mahasiswa } \\
\text { magang } \\
\end{array}$ \\
\hline
\end{tabular}

Sumber: Analisis pribadi

Dari tabel diatas terlihat lebih banyak tantangan dibandingkan kelebihannya. Solusi yang dilakukan biro arsitek untuk mengatasi hal tersebut adalah sesekali melakukan pertemuan langsung antara tim di biro arsitekdengan mahasiswa magang. Pertemuan tersebut dilakukan satu bulan sekali dengan protokol kesehatan. Disamping itu dibentuk tim khusus yang disebut dengan mentor untuk mendampingi intens serta 
bertugas mengkoordinasi perkembangan magang.

\section{Kesimpulan}

Dari analisis yang dilakukan terhadap cara berkomunikasi baru bisa ditarik kesimpulan: Komunikasi biro arsitek dengan klien memang dilakukan secara daring, tetapi untuk perkenalan awal dan survei lokasi dilakukan secara offline dengan protokol kesehatan. Komunikasi biro arsitek dengan tim dilakukan secara intens agar persepsi dan target bisa tercapai. Kendala utama adalah jaringan yang tidak sama di setiap lokasi rumah masing masing tim. Sehingga terkadang juga diadakan pertemuan di kantor untuk berkoordinasi.

Komunikasi biro arsitek dengan mahasiswa magang lebih banyak tantangannya karena mahasiswa magang belum punya banyak pengalaman tentu membutuhkan bimbingan yang intens dan itu sulit dicapai dengan sistem daring.

Perubahan komunikasi di era new normal kaitannya dengan postkolonialisme Homi $\mathrm{K}$ Bhabha yaitu adanya ruang ketiga diantara cara berkomunikasi offline dan online. Kedua hal tersebut saat ini bukan sebagai bagian terpisah tetapi berpadu sebagai alternatif dan solusi baru dalam komunikasi sebuah biro arsitek sekarang baik dengan tim, mahasiswa magang maupun klien.

\section{Daftar Pustaka}

Bhabha, H. K. 1994. Introduction: location of culture. London dan New York: Routledge Taylor \& Francis e-Library
Bhabha, H. K. 2007. The location of culture. New York: Routledge

Deleuze, G., Guattari F. 1980. Capitalisme et schizophrénie. L'anti-CEdipe. Les Editions de Minuit, Viking Penguin.

DeRossette, Glenn, Z. 2016. Variation in job performance among telecommuters. A thesis submitted to the faculty of san francisco state university. San Francisco, California.

Gilster, P. 1997. Digital literacy. Meridian

Groat, L. \& Wang. 2002. D. Architectural research methods. New York: John Wiley \& Sons.

Huuhtanen, P., 1997. The health and safety issues for teleworkers in the European Union. Consolidated report. European Foundation for the Improvement of Living and Working Conditions. Working Paper No: WP/97/29/EN.

Mungkasa, O. 2020. Bekerja Jarak Jauh (Telecommuting): Konsep, Penerapan dan Pembelajaran. Bappenas Working Papers Volume III No. 1 - Maret 2020

Poster, M. 1995. The Second Media Age. Cambridge: Polity Press. 